Société d'histoire de la révolution de 1848 et des révolutions du XIXe siècle

$50 \mid 2015$

Sociétés et forces de sécurité au $\mathrm{XIX}^{\mathrm{e}}$ siècle

\title{
Philippe BOURDIN [dir.], Les nuits de la Révolution française, Clermont-Ferrand
}

Presses universitaires Blaise-Pascal, 2013, 460 p. ISBN :

978-2-84516-607-3. 25 euros.

\section{Sophie Panziera}

\section{(2) OpenEdition}

Édition électronique

URL : http://journals.openedition.org/rh19/4845

DOI : $10.4000 /$ rh 19.4845

ISSN : $1777-5329$

Éditeur

La Société de 1848

Édition imprimée

Date de publication : 1 juillet 2015

Pagination : 207-208

ISSN : 1265-1354

\section{Référence électronique}

Sophie Panziera, «Philippe BOURDIN [dir.], Les nuits de la Révolution française, Clermont-Ferrand », Revue d'histoire du XIXe siècle [En ligne], 50 | 2015, mis en ligne le 01 juillet 2015, consulté le 24 septembre 2020. URL : http://journals.openedition.org/rh19/4845 ; DOI : https://doi.org/10.4000/ rh19.4845

Ce document a été généré automatiquement le 24 septembre 2020

Tous droits réservés 


\section{Philippe BOURDIN [dir.], Les nuits de la Révolution française, Clermont- Ferrand}

Presses universitaires Blaise-Pascal, 2013, 460 p. ISBN :

978-2-84516-607-3. 25 euros.

\section{Sophie Panziera}

\section{RÉFÉRENCE}

Philippe BOURDIN [dir.], Les nuits de la Révolution française, Clermont-Ferrand, Presses universitaires Blaise-Pascal, 2013, 460 p. ISBN : 978-2-84516-607-3. 25 euros.

1 Issu d'un colloque organisé à Clermont-Ferrand en septembre 2011, cet ouvrage collectif s'inscrit dans la continuité des recherches sur les pratiques et les représentations de la nuit initiées par Simone Delattre et Alain Cabantous ${ }^{1}$. L'originalité de l'approche réside dans la prise en compte d'une nuit bouleversée, modifiée et réorganisée par l'épisode révolutionnaire, et non plus consacrée aux activités habituelles de la veille ou du repos. L'ouvrage se propose d'aborder non seulement la nuit insurrectionnelle, mais aussi son influence sur la vie quotidienne qui accompagne ces événements. Il est pour cela divisé en quatre parties: «Le temps de l'action politique ", «Les travaux de la nuit », "Sociabilités nocturnes" et «Imaginaires et représentations ». L'étude de la Révolution française de 1789 est privilégiée, mais le XIX ${ }^{e}$ siècle est également abordé.

2 À la lecture des différentes contributions, force est de constater que la révolution est avant tout diurne. La plupart des moments insurrectionnels se déroulent en effet à la lumière du jour, afin d'asseoir leur légitimité et de rendre visible l'action révolutionnaire. La nuit est associée à un imaginaire négatif; elle est le temps du complot, de la conspiration et de l'illégalité. Jean-Claude Caron montre ainsi que les « journées » de 1830, de 1848 et de 1871 ont « besoin de la lumière du jour pour mettre 
en scène, par le mot ou par l'image, le geste héroïque des combattants : partisans de l'insurrection comme forces du maintien de l'ordre»(p.130). Rares sont donc les «nuits révolutionnaires", qui ne sont souvent que le prolongement d'un mouvement commencé plus tôt dans la journée; il faut alors illuminer l'action en cours, afin d'effacer le caractère nocturne de l'événement.

Quelle est par conséquent la pertinence d'aborder la nuit pendant la Révolution? Cette question est d'emblée posée par Alain Cabantous, qui montre comment nuit et événement révolutionnaire sont a priori deux éléments opposés. Au fil de l'ouvrage, on voit cependant bien une nuit particulière se dessiner, pas une nuit de combats certes, mais une nuit constituée de temporalités multiples, qui devient le temps de la discussion et de l'échange, de la préparation de la journée à venir, de la législation et de l'organisation. Elle est également le temps de la réjouissance et de la fête. Guillaume Mazeau montre par exemple comment les spectacles pyrotechniques deviennent un moment important de la vie politique, s'imposant comme un rituel de cohésion et de célébration collective. L'épisode révolutionnaire investit et modifie ainsi le temps nocturne, plus particulièrement la soirée, et participe en cela à la «conquête de la nuit ». Pour Pierre Serna, la Révolution française voit également la naissance d'une nouvelle temporalité politique, qui dans sa nécessité d'investir l'ensemble du temps disponible, efface la distinction diurne/nocturne, légiférant en continu, de nuit comme de jour. On retrouve cet effacement de la nuit durant la Commune de Paris (Jean-Claude Caron).

4 Par ailleurs, les dispositifs de contrôle urbain mis en place par les autorités sont bouleversés. Les systèmes d'éclairage sont d'ailleurs souvent choisis pour cible dès les premiers moments de protestation car ils sont le symbole du pouvoir ; c'est le cas lors de l'agitation libérale des années 1820 étudiée par Samuel Guicheteau. Les nouvelles autorités prennent cependant vite le relais, instituant un contrôle accru de l'ensemble des activités nocturnes, en imposant par exemple un couvre-feu sur la pêche de nuit en Seine-Inférieure au début du XIX ${ }^{\mathrm{e}}$ siècle (Romain Grancher).

5 La nuit en révolution se compose donc de temporalités plurielles; elle est fragmentée et instaure un nouveau quotidien. C'est l'un des principaux apports de cet ouvrage : décomposer la nuit et étudier ses différentes inflexions et non plus la considérer comme un temps uniforme. Pierre Serna distingue ainsi plusieurs moments : la soirée, prolongement de l'action diurne et d'activités multiples, puis le creux de la nuit, temps de peur, de contrôle, mais aussi de repos, avant le réveil au petit matin.

6 Enfin, s'il n'existe que très peu de nuits insurrectionnelles à proprement parler, les différentes contributions dessinent, en la déconstruisant, une nuit révolutionnaire fantasmée très présente dans l'imaginaire et l'historiographie. Une partie de ces représentations semble se forger au XIX ${ }^{e}$ siècle. Pour Paul Chopelin, la figure du prêtre réfractaire célébrant la messe nocturne est ainsi développée sous la plume des historiens républicains, et notamment de Michelet, qui en font une des clés de la fabrique du fanatisme religieux. Dans le même temps, cette figure entre dans la mythologie catholique, devenant un passage obligé des romans édifiants et renvoyant à la persécution des premiers chrétiens. C'est également au XIX ${ }^{\mathrm{e}}$ siècle que se dessine la figure d'un Robespierre délaissant le sommeil pour réaliser ses idéaux révolutionnaires (Guillaume Garnier), alors que Lafayette est représenté comme un " général Morphée " (Michel Biard). Cette étude ouvre ici des perspectives de recherche sur l'évolution des représentations de ces nuits révolutionnaires, notamment au XIX ${ }^{\mathrm{e}}$ siècle. 
7 Stimulante, la lecture de cet ouvrage invite donc les historiens de toutes les périodes à s'interroger sur la "nocturnité » effective des " nuits historiques », et plus largement à intégrer à leur réflexion cette multiplicité de la nuit, qu'elle relève du quotidien ou de l'exceptionnel.

\section{NOTES}

1. Simone Delattre, Les douze heures noires. La nuit à Paris au XIX ${ }^{e}$ siècle, Paris, Albin Michel, 2000 ; Alain Cabantous, Histoire de la nuit. XVII ${ }^{e}$-XVIII ${ }^{e}$ siècle, Paris, Fayard, 2009. 